\title{
Fatty acid composition, total phenolic contents and antioxidant activity of white and black sesame seed varieties from different localities of Ethiopia
}

\author{
Misganaw Gedlu Agidew ${ }^{1}$, Amare Aregahegn Dubale ${ }^{1}$, Minaleshewa Atlabachew ${ }^{2 *} \mathbb{D}$ and Wasihun Abebe ${ }^{2}$
}

\begin{abstract}
Background: Authentication of food and agricultural products is important to trace out the right product and ensure the customer's preference and their health. Sesame (Sesamum indicum L.) is one of the most important crops used for food and medicine in Ethiopia and different varieties and cultivars are produced in different regions of the country. This study was undertaken to determine the total flavonoid content, total phenolic content, antioxidant activity, and fatty acids profile of black and white sesame seed varieties. Samples were obtained from three major sesame seed-producing districts of Ethiopia.
\end{abstract}

Results: The total phenolic content (TPC), total flavonoid content (TFC), and the half-maximal inhibitory concentration $\left(\mathrm{IC}_{50}\right)$ were ranged from 2.95 to $6.95 \mathrm{mgGAE} / \mathrm{g}, 2.13-4.99 \mathrm{mgCE} / \mathrm{g}$ and 8.3-16.8 AAE/g of the sample, respectively. In general, white sesame seed samples showed the highest TPC, TFC, and antioxidant activity than the black variety. Location wise, samples collected from the Metema district were found to contain a relatively higher concentration of the phytochemicals. The white seed variety was characterized by significantly higher content of oil $(53.2-58.2 \%$ by mass of the sample) than the back variety (47.6-51.4\%). The oil content of the seeds was found to contain nine identifiable fatty acids (FAs). The total unsaturated fatty acids constituted more than $82 \%$ of the total FAs, while the saturated FAs were lower than $18 \%$ of the total FAs. Among the unsaturated FAs, linoleic acid (C18:2, omega- 6 FAs) was the dominant FA (42.5-44.3\%) followed by oleic acids (37.2-38.9\%). On the other hand, palmitic acids (9.35-11.2\%) and stearic acid (5.78-6.52\%) were the dominant FAs among the saturated FAs.

Conclusions: The studied samples had higher concentration of linoleic acid (omega-6 FA) than oleic acid, as opposed to other reported accessions of sesame seeds. Furthermore, white sesame seeds were richer in oil content than the black variety. The high concentration of unsaturated FAs, omega- 6 FA, and phenolic compounds make sesame seeds nutritionally and medicinally important for the human diet. Unlike the fatty acids profiles, the level of phenolic compounds in sesame seeds was highly dependent on the geographical region and varietal type of the seeds.

Keywords: Antioxidant activity, Fatty acids, Flavonoids, Sesamum indicum L., Total phenolics, GC/MS

\footnotetext{
*Correspondence: atminale2004@yahoo.com

2 Department of Chemistry, College of Science, Bahir Dar University, P. O.

Box 79, Bahir Dar, Ethiopia

Full list of author information is available at the end of the article
}

\section{Background}

The demand for vegetable oil has been increasing as most indigenous plants and seeds are rich in essential nutrients and also have a wide range of medicinal values [34]. Sesame (Sesamum indicum L.) is an oilseed herbaceous crop of the Pedaliaceae family, which 
is produced by only a few developing countries in the world due to its high demand for labor farming and harvesting [43]. About $96 \%$ of the world sesame production is contributed from Asia and African countries. Considering a 10-year average report (from 2008 to 2018), the top ten sesame producers are Myanmar, India, Tanzania, Sudan, China, Nigeria, Sudan (Former), Ethiopia South Sudan, and Burkina Faso, in the same order (http://www.fao.org/faostat/en/\#data/QC/ visualize, accessed on 8th July 2020).

Sesame is an important annual oilseed crop being cultivated as an ingredient for human food oil, meal, and animal feeds [35, 36]. The sesame seed oil contains saturated fatty acid, unsaturated fatty acids, proteins, and various minor nutrients such as vitamins and minerals, lignans, such as sesamin, sesamol, sesamolin, and tocopherols $[11,14,25]$. The seeds are also very rich in iron, magnesium, copper, calcium, and vitamin B1 (thiamine) and $\mathrm{E}$ (tocopherol), and phytosterols [20, $21,35]$. Sesame seed oil is renowned for its stability because it strongly resists oxidative rancidity even after long exposure to air [13].

These days, there are several varieties and genotypes of sesame adapted to different geographical conditions. However, the cultivation of modern varieties is limited due to insufficient genetic information [41]. According to some studies the seed is believed to exist in 16 genera and 60 species, most of which exist in Africa [41]. Ethiopia is the six top sesame producers in the world [30]. Due to the high market demand and adaptability to several environmental factors, sesame production is increasing year to year in different countries [43]. In Ethiopia, sesame seed production and export alone is twice larger than all other oil seeds together. Humera, North Gondar, and Wollega zones are the major sesame-growing areas in the country for local consumption and export market [43]. The latter two zones produce more than $60 \%$ of the country's total sesame annual yield [26]. In these areas, both black and white sesame seed varieties are cultivated but the oil yield, the dominant fatty acid constitutes of the oils and phenolic compounds of these sesame seed varieties cultivated in these districts have not be reported so far, though the country is one of the major sesame seed producers and exporters from Africa. Furthermore, these sesame seed varieties have not been compared and reported in terms of the aforementioned chemical constituents.

Authentication of food and agricultural products is important to trace out the right product and ensure the customer's preference and their health [10, 12]. However, as sesame seed is cultivated only in some parts of the world, few reports were documented in the literature about the oil content and other phytochemicals. In general, the composition of plant phytochemicals varies within the different species types, varietal types, and accession types [28]. Thus, it is the pressing demand to characterize plant foods and relates the finds with accessions, varieties, and/ or species investigated to relate their quality based on their chemical constituents. Therefore, the present study was aimed to provide information about total flavonoid content, total phenolic content, antioxidant potential, and fatty acids composition in Ethiopian sesame seed.

\section{Materials and methods}

\section{Sample collection}

Although sesame seeds are cultivated in different regions of Ethiopia, the Metema and Wollega types are the two major sesame seeds constituting more than $60 \%$ of the country's export market of Sesame $[1,5,26]$. These two types are produced in North Gondar zone of Amhara and East Wollega zone of Oromia regions, respectively. For this study, three districts that consistently cultivate sesame in cluster-wise manner were selected. These include: West Armachiho and Metema districts from North Gondar zone while Amuru district was considered from East Wollega zone. From each district, two to three subdistricts were selected and a total of eight sub-districts were considered for this study, namely: Gabila, Mahrish, and Girarwuha from West Armachiho district, Meka, Akushra, and Lancha from Metema district; and Yaahaa and Qaqaro from Amuru district.

From each sub-districts, five farmers were selected and from each farmer, $500 \mathrm{~g}$ of each of black and white sesame seeds was collected during March-April, 2018. Samples of the same variety from different sub-district of the same district were composited or mixed to get a bulk sample. Since, the same climate condition and soil type are expected to exist in those sub-districts of the same district.

\section{Chemicals and reagents}

All reagents used in this study were of analytical grade and directly used as received. Methanol (HPLC and spectroscopy grade), chloroform (99.5\%), $n$-hexane (AR grade, 99\%), acetone (AR grade, 99.5\%), aluminum chloride (99.9\%, anhydrous), sodium carbonate (AR), sodium chloride, sulfuric acid (98\%), sodium hydroxide extra pure pellet, and L-ascorbic acid (AR, 99.7\%) were from Research Lab Fine Chem, Mumbai, India; toluene (99.99\%), D-Catechin hydrate (96\%, HPLC grade), gallic acid monohydrate (99\%, HPLC grade), undecanoic acid, and 2-diphenyl-2-picrylhydrazyl (DPPH) were from Sigma Aldrich, Germany; anhydrous sodium sulfate (99$101 \%)$, sodium tungstate dehydrate (99\%), phosphomolybdic acid hydrate $(99+\%)$, and Ortho-phosphoric acid (85\%) were from Fisher Scientific, USA. 


\section{Analysis of phenolic compounds and antioxidant activity of seed extracts}

For the determination of the total flavonoids, total phenolic and antioxidant activity of sesame seed varieties, about $1 \mathrm{~g}$ of powdered seed was extracted under ultrasonic water bath at $50{ }^{\circ} \mathrm{C}$ for $2 \mathrm{~h}$ using $25 \mathrm{~mL}$ of absolute methanol (100\%) and $80 \%$ methanol in water.

The total flavonoid content was determined following the method reported by Mistrello et al. [29] and Bayba et al. [8]. Exactly $0.2 \mathrm{~mL}$ of extract was dissolved in $3.5 \mathrm{~mL}$ of distilled water in the test tube, and then, $0.3 \mathrm{~mL}$ of $5 \%$ sodium nitrite $\left(\mathrm{NaNO}_{2}\right)$ was added to the mixture and kept for $5 \mathrm{~min}$. Then $0.3 \mathrm{~mL}$ of $10 \%$ aluminum chloride $\left(\mathrm{AlCl}_{3}\right)$ and $2 \mathrm{~mL}$ of $4 \%$ sodium hydroxide $(1 \mathrm{M}$ $\mathrm{NaOH}$ ) was added and allowed to stand for another $5 \mathrm{~min}$. Finally, the solution was measured for total content using UV-Vis spectrophotometer at $510 \mathrm{~nm}$. D-Catechin was used as a reference standard and data were reported as $\mathrm{mg}$ catechin equivalent per gram of sample (mgCE/g).

Total phenolic content in the extract was determined according to the procedure reported by Bayba et al. [8]. Briefly, $0.2 \mathrm{~mL}$ of each extract was mixed with $0.75 \mathrm{~mL}$ of Folin reagent and $3.75 \mathrm{~mL}$ of $7 \%$ sodium carbonate. Finally, the mixture was incubated at room temperature in the dark for 30 min and absorbance was measured at $760 \mathrm{~nm}$. Then, the total phenolic content was expressed as mg gallic acid equivalents per gram (GAE)/g.

Antioxidant activity was determined according to the procedure of Rebaye et al. [32] with some modification. Different volumes $(5,10,20,40,50,75$, and $100 \mu \mathrm{L})$ of the sample extracts were taken in a separate test tube and $2 \mathrm{~mL}$ of $0.004 \%$ solution of DPPH was added to each of the test tube containing the extracts. Then, the volume of each test tubes was adjusted to $5 \mathrm{~mL}$ with methanol and absorbance was measured at $517 \mathrm{~nm}$. Ascorbic acid was used as a reference standard while mixture without extract was used as control. Inhibition of free radical $\mathrm{DPPH}$ in percent $(I \%)$ was then calculated as follows:

$$
\text { Inhibition }(\mathrm{I} \%)=\frac{(\mathrm{A} 0-\mathrm{A} 1)}{\mathrm{A} 0} \times 100,
$$

where $A_{0}$ is the absorbance of the control and $A 1$ is the absorbance of the sample. The extract concentration providing $50 \%$ of radical scavenging activity $\left(\mathrm{IC}_{50}\right)$ was calculated from the graph of inhibition percentage against extract concentration.

\section{Determination of fatty acids}

Prior to extraction, all the samples were stored at room temperature in a plastic bag. Approximately, $15 \mathrm{~g}$ of sample was finely ground with electrical blender (FW100 high-speed universal disintegrator) and portion of the powdered sample was immediately extracted by the Folch method cited in Rincón-Cervera et al. [33] with a slight modification. Briefly, a $0.5 \mathrm{~g}$ portion of powder sample was mixed with $8 \mathrm{~mL}$ chloroform and $4 \mathrm{~mL}$ methanol and undergone shaking for $36 \mathrm{~h}$ at $300 \mathrm{rpm}$ in the dark room. Then, the lipid phase (chloroform) was separated from the aqueous phase with the aid of $2.4 \mathrm{~mL}$ of $0.73 \%$ aqueous sodium chloride solution. The solvent (chloroform) was then removed using rotary evaporator at $40{ }^{\circ} \mathrm{C}$. Finally, the resulting dry sample was recovered with 5.00$\mathrm{mL}$ toluene, placed in a brown bottle and stored at $4{ }^{\circ} \mathrm{C}$ for derivatization and fatty acid analysis.

For derivatization, $2 \mathrm{~mL} \mathrm{H}_{2} \mathrm{SO}_{4}$ in methanol (1\%) was added into a test tube containing $1 \mathrm{~mL}$ previously extracted lipid. To this, $175 \mu \mathrm{L}$ of $0.1697 \mathrm{mg} / \mathrm{mL}$ undecanoic acid (C11:0) was added as an internal standard and the tube was tightly caped. Once the mixture was homogenized, it was allowed to react for $12 \mathrm{~h}$, while being incubated at $50{ }^{\circ} \mathrm{C}$. The solution was left to cool down at room temperature and $5.0 \mathrm{~mL}$ of $5 \%$ aqueous $\mathrm{NaCl}$ solution was added. Then, the fatty acids methyl esters (FAMES) were extracted twice with $3.0 \mathrm{~mL}$ of hexane (total $6 \mathrm{~mL}$ of hexane). Once the extract was dried over anhydrous sodium sulfate and filtered by an acrodisc syringe membrane filter, then it was transferred into the $\mathrm{GC} / \mathrm{MS}$ analysis vial and stored at $-20{ }^{\circ} \mathrm{C}$ until analysis was done [27].

\section{GC/MS analysis}

Agilent 7890B gas chromatograph equipped with a 5977A MSD was used. This was coupled to a mass spectrometer operated in electron ionization mode. A fusedsilica capillarity column (30 m, $0.25 \mathrm{~mm}$ I.D., $0.25 \mathrm{~mm}$ film thickness) with chemically bonded phases DB-5 MS (J and W Scientific) was used for the GC separation. A split injection mode was used and a $1-\mu \mathrm{L}$ sample was injected. The starting oven temperature was $125^{\circ} \mathrm{C}$, this was held for $2 \mathrm{~min}$ then raised at the rate of $30{ }^{\circ} \mathrm{C} / \mathrm{min}$ to $170{ }^{\circ} \mathrm{C}$, then raised at the rate of $15^{\circ} \mathrm{C} / \mathrm{min}$ to $200{ }^{\circ} \mathrm{C}$ hold for $2 \mathrm{~min}$, then raised at the rate of $3^{\circ} \mathrm{C} / \mathrm{min}$ to 230 ${ }^{\circ} \mathrm{C}$, this was held for $20 \mathrm{~min}$. Other operating conditions were as follows: carrier gas, He (99.999\%), with a flow rate of $1 \mathrm{~mL} / \mathrm{min}$; injector temperature, $250^{\circ} \mathrm{C}$; and split ratio 25:1. Mass spectra were recorded at $70 \mathrm{eV}$ and the mass range was from $\mathrm{m} / \mathrm{z} 40$ to $500 \mathrm{amu}$, ion source temperature $230{ }^{\circ} \mathrm{C}$ and quadruple temperature $150{ }^{\circ} \mathrm{C}$ and solvent delay time $3.5 \mathrm{~min}$. The fatty acids were identified by making use of spectral matching of each GC/MS spectra with the NIST-11 library data for the GC/MS system.

\section{Data analysis}

Descriptive statistical analysis was done and the results were expressed as mean values and standard deviation 
(SD) of triplicate measurements. Significant differences of the data among the parameters were done by one-way ANOVA. All the statistical tests were performed at 5\% level of significance.

\section{Results and discussion}

Total flavonoid, total phenolic content, and antioxidant activity

Total flavonoid content of the extracts was determined by extrapolation from the calibration curve $Y=0.0547 x-0.0054 ; \quad\left(R^{2}=0.9995\right) \quad$ prepared from absorbance measurement at $510 \mathrm{~nm}$ on the catechin standard solution while phenolic content was determined by extrapolation from the calibration curve $Y=0.0619 x-0.0049\left(R^{2}=0.9999\right)$ constructed from gallic acid standard. The level of total flavonoid and phenolic contents are given in Table 1. The effect of $100 \%$ methanol and $80 \%$ methanol on the extraction efficiency for phenolic and flavonoid content was compared (results not shown) and $80 \%$ methanol was found to be more efficient than absolute methanol. The effect of 1:1 ration of water to methanol was also tested but the resulting extract was turbid and cloudy and hence greatly affected the absorbance measurement. Thus, $80 \%$ methanol was used for the extraction of flavonoids and phenolic compounds from the studied samples. Aqueous methanol (80\%) also proved to be effective solvent for extracting phenolic compounds from rapeseed [15] and flaxseed [4].

Looking at Table 1, the total phenolic content in sesame seed varieties ranged from 2.95 to $6.96 \mathrm{mgGAE} / \mathrm{g}$ of sample. While total flavonoid content ranged from 2.13 to $4.99 \mathrm{mgCE} / \mathrm{g}$. Comparing the different districts of sesame seed samples, samples from Metema district had significantly higher total phenolic (6.96 mgGAE/g) and flavonoid content $(4.99 \mathrm{mgCE} / \mathrm{g})(p<0.05)$ than any other districts (Table 1 ) while significantly lower concentration $(p<0.05)$ of TPC $(2.95 \mathrm{mgGAE} / \mathrm{g})$ and TFC $(2.13 \mathrm{mgCE} / \mathrm{g}$ ) were recorded in samples from Amuru and West Armachiho districts, respectively.
In general, white sesame seed varieties had a relatively higher concentration of TPC and TFC than the corresponding black sesame seed samples collected from the same districts. White sesame seed sample from the West Armachiho district contained almost twice the concentration in the black seed variety.

A study on Moroccan sesame seed showed a much lower concentration of total flavonoids expressed as quercetin equivalent (QE) $(0.13-0.15 \mathrm{mgQE} / \mathrm{g})$ and total phenolics (3.58-3.98 $\mathrm{mgGAE} / \mathrm{g}$ ) [34] but the varieties of the studied sesame seeds were not indicated in the report. On the other hand, a Chinese white sesame seed had a significantly higher concentration of flavonoids (7.14-13.55 mgCE/100 g) and a comparable total phenolic content (3.71-7.9 mgGAE/g) [25].

In this study, the antioxidant activity of the $80 \%$ methanol extracts of the seeds was investigated. The DPPH scavenging activity of the sesame seed extracts with an increase in the concentration of the samples is depicted in Fig. 1a, b. As indicated in the figures, all the samples had closely matching inhibition activity but much lower than the standard ascorbic acid, which is one of the potent antioxidant compounds. From the figure, the concentration (in $\mu \mathrm{g} / \mathrm{mL}$ ) of the sample that is required to reduce the $\mathrm{DPPH}$ by $50 \%$ (i.e., $\mathrm{IC}_{50}$ value) are $159,262,203,274$, 256, 317, and 2.62, respectively, for Metema type white sesame, Metema type Black sesame, West Armachiho type white sesame, West Armachiho type black sesame, Amuru type white sesame, Amuru type Black sesame and ascorbic acid standard, respectively. Thus, Metema type white sesame had relatively better inhibition capacity while Black sesame from Amuru district had the lowest inhibition capacity.

To visualize the inhibition capacity of the samples with respect to ascorbic acid, all the $\mathrm{IC}_{50}$ values showed in the figure above are converted to ascorbic acid equivalent, and results are presented in Table 1 . From the data in Table 1, the sesame seeds extracts showed lower DPPH scavenging activity $(p<0.05)$ than that of the standard ascorbic acid. The present study revealed that $\mathrm{IC}_{50}$ values were determined between $8.23 \pm 0.89$ and

Table 1 Total flavonoid and total phenolic contents, and antioxidant activity of sesame seed extracts

\begin{tabular}{|c|c|c|c|c|}
\hline Districts & Sesame seed varieties & $\begin{array}{l}\text { Total flavonoid contents (TFC) } \\
(\mathrm{mg} / \mathrm{g})\end{array}$ & $\begin{array}{l}\text { Total phenolic contents } \\
(\mathrm{mg} / \mathrm{g})\end{array}$ & $\begin{array}{l}\text { Scavenging activity } \\
\left(\mathrm{IC}_{50}\right) \text { value (mgAAE/g) }\end{array}$ \\
\hline \multirow[t]{2}{*}{ Metema } & White & $4.99 \pm 0.03^{\mathrm{a}}$ & $6.96 \pm 0.03^{\mathrm{a}}$ & $16.8 \pm 1.59^{\mathrm{a}}$ \\
\hline & Black & $3.38 \pm 0.02^{b}$ & $4.27 \pm 0.05^{b}$ & $10.2 \pm 1.202^{b}$ \\
\hline \multirow[t]{2}{*}{ West Armachiho } & White & $4.17 \pm 0.03^{c}$ & $5.26 \pm 0.05^{c}$ & $13.2 \pm 1.195^{c}$ \\
\hline & Black & $2.13 \pm 0.03^{d}$ & $4.19 \pm 0.08^{d}$ & $9.8 \pm 0.96^{d}$ \\
\hline \multirow[t]{2}{*}{ Amuru } & White & $4.34 \pm 0.1^{\mathrm{e}}$ & $4.59 \pm 0.06^{\mathrm{e}}$ & $10.4 \pm 0.97^{b}$ \\
\hline & Black & $2.89 \pm 0.1^{f}$ & $2.95 \pm 0.04^{f}$ & $8.3 \pm 0.80^{e}$ \\
\hline
\end{tabular}

NB: Data represent mean \pm SD of triplicate analysis. Means within a column $(a, b, c, d, e, f)$ marked with different letters are significantly different at $(p<0.05)$ 

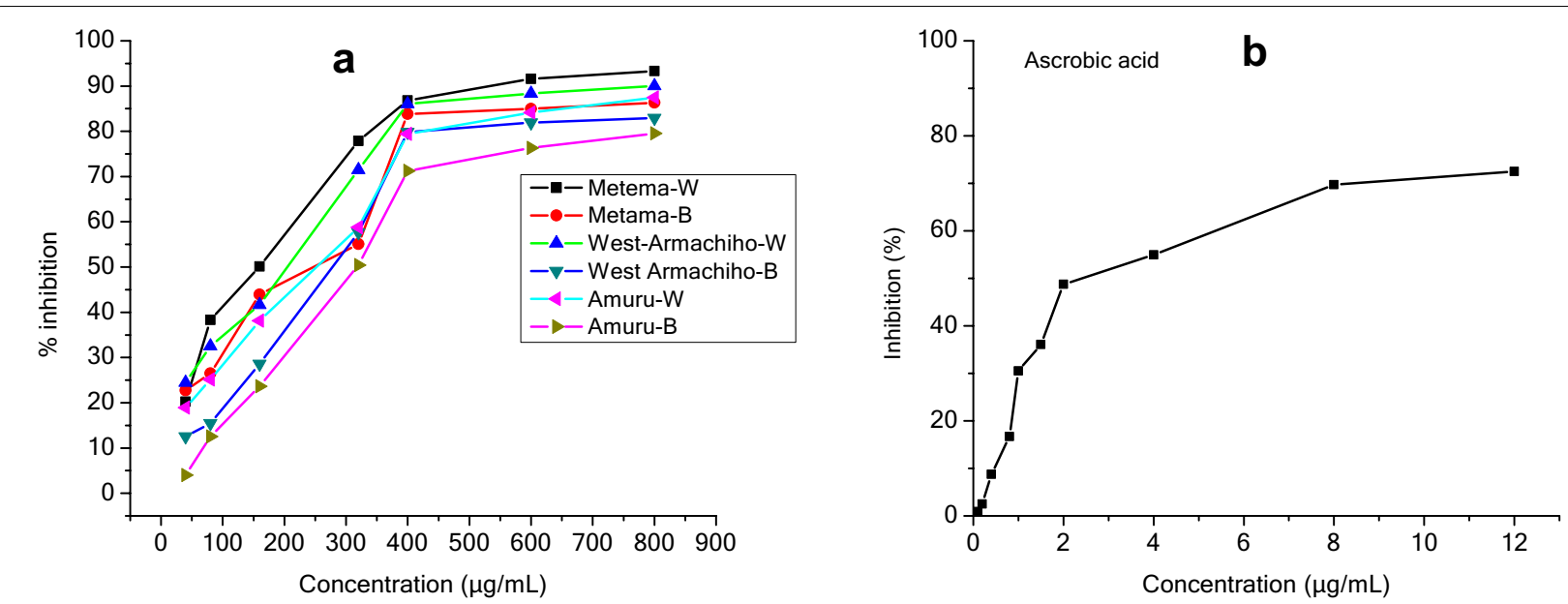

Fig. $1 \mathbf{a}, \mathbf{b} \%$ Inhibition vs concentration graph of two varieties of sesame seed samples (a) and ascorbic acid standard (b). The suffix "W" and "B" refers to "White" and "Black" variety, respectively

$16.8 \pm 1.59 \mathrm{mgAAE} / \mathrm{g}$ of sesame seed varieties. These observed differences may be attributed to factors such as genetic variation difference, geographical factors, soil type, agriculture practices, and climate condition of the sampling districts.

\section{Correlation between antioxidant activity and phenolic compounds}

In order, visualize the dependence of the antioxidant activities on the total phenolic and flavonoid contents, correlation analysis was carried out. It was found that the regression coefficient $\left(r^{2}\right)$ between $\mathrm{IC}_{50}$ in $(\mathrm{mgAAE} / \mathrm{g})$ and phenolic compounds (Fig. 2a), and between $\mathrm{IC}_{50}$ (in mgAAE/g) and flavonoids (Fig. 2b) of the two varieties of samples was found to 0.94 and 0.5 , respectively. Both flavonoid and phenolic compounds had a positive correlation with antioxidant activity. However, phenolic compounds were more contributors to the antioxidative properties of the extracts of sesame seed samples.

\section{Fatty acid analysis}

The total oil content of the sesame extract ranged from 47.6 to $58.2 \%$. The white variety of sesame seeds had relatively higher oil yield than the corresponding black variety. The average oil yield of the samples are arranged in a decreasing order: West Armachiho type white seed $(58.2 \%)>$ Metema type white seed $(56.2 \%)>$ Amuru type white seed $(53.2 \%)>$ Amuru type black seed $(51.4 \%)>$ Metema type black seed $(48.5 \%)>$ West Armachiho type black seed (47.6).

Various researchers have reported the oil percentage composition of sesame seeds collected from different counties. The percentage oil content found in the present study were in agreement with the report by Azeez et al.
[6] (53.23-55.12\%), Hiremath et al. [23] (46.13-53.8\%), Benitez-Benitez et al. [9] (51\%) and Carvalho et al. [11] (58\%). However, lower percentage oil yield (35-49\%) was reported by several scholars for sesame seed collected from Africa, Uruguay and Iran [2, 17, 42]. On the other hand, unlike the present findings where white sesame seeds found to contain higher oil yield, a report by Ali et al. [3] have shown that black sesame seeds from Pakistan had a higher percentage composition of oil (52\%) than the corresponding white variety (44\%).

As indicated in the literature, extraction protocol, agronomic practice, year of cultivation, accession type and environmental conditions of the cultivation regions have significant effect on the oil yield of sesame seeds $[3,9,24,42]$.

The composition of fatty acids of sesame seed varieties was determined by gas chromatography-mass spectrometry (GC/MS). A representative total ion chromatogram is indicated in the Additional file 1 (Figures S1-S6). In all the studied samples, a total of nine major fatty acids were detected and their identities were confirmed from NIST-11 spectral library. The identified compounds are palmitoleic acid, palmitic acid, margaric acid, linoleic acid, Oleic acid, cisvaccenic acid, stearic acid, arachidic acid, and behenic acid (Table 2). From the nine identified FAs, palmitic (C16:0), heptadecanoic acid (C17:0), octadecanoic acid (C18:0), eicosanoic acid (C20:0) and docosanoic acid (C22:0) were saturated fatty acids while palmitoleic acid (C16:1), oleic acid (C18:1), cis-vaccenic acid (18:1) and linoleic acid (C18:2) were unsaturated fatty acids.

The percentage composition of some of the fatty acids varied within sesame seed varieties over a narrow range. For example, the stearic acid varied from (5.78 

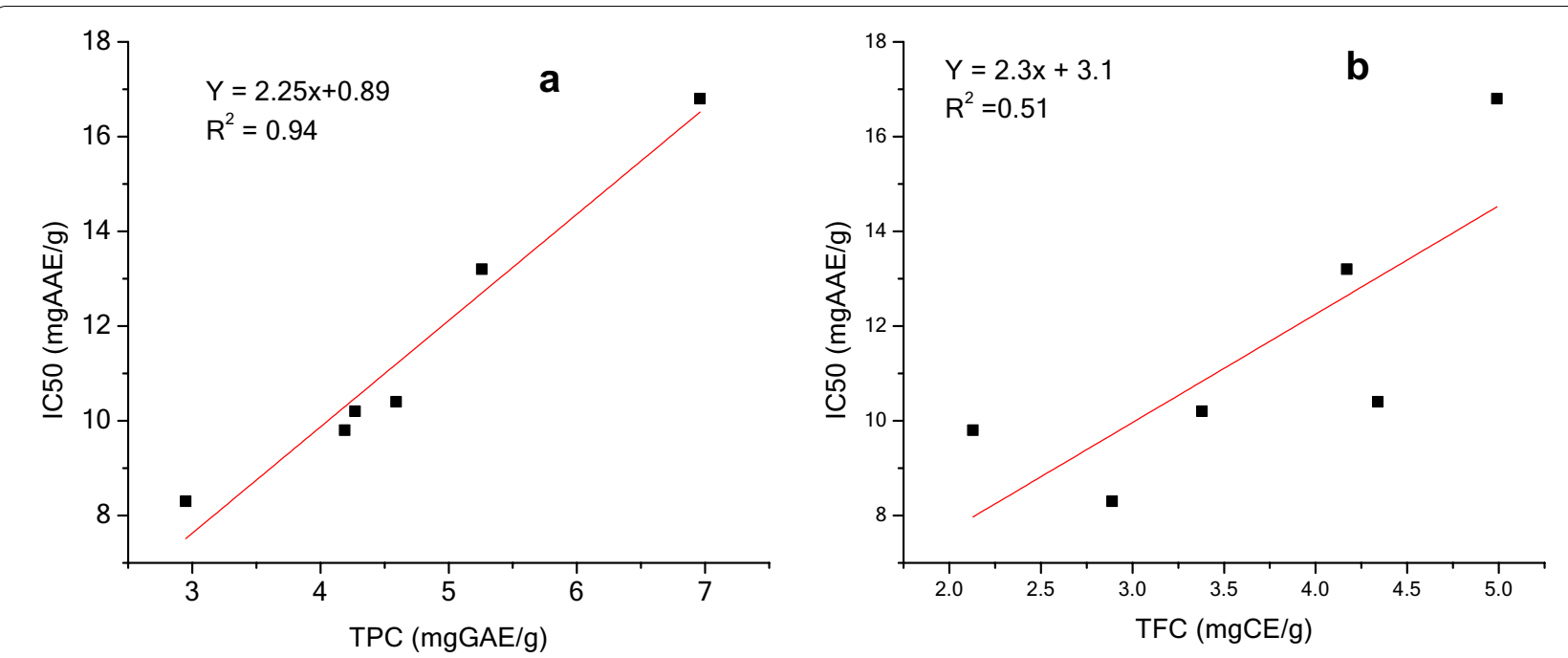

Fig. 2 a, b Correlation between the antioxidant activities with total phenolic content (a) and with total flavonoid content (b)

Table 2 Relative percentage composition (\%) of fatty acids detected in white and black sesame seed varieties collected from three different districts (Metema, West Armachiho and Amuru) in Ethiopia

\begin{tabular}{|c|c|c|c|c|c|c|c|}
\hline \multirow[t]{2}{*}{ Fatty acid } & \multicolumn{6}{|c|}{ Fatty acid composition (\%) (mean \pm standard deviation; $n=2)$} & \multirow[b]{2}{*}{$\begin{array}{l}\text { Means } \\
\text { of the average }\end{array}$} \\
\hline & $\begin{array}{l}\text { Metema white } \\
\text { seed }\end{array}$ & $\begin{array}{l}\text { Metema black } \\
\text { seed }\end{array}$ & $\begin{array}{l}\text { West } \\
\text { Armachiho } \\
\text { white seed }\end{array}$ & $\begin{array}{l}\text { West } \\
\text { Armachiho } \\
\text { black seed }\end{array}$ & $\begin{array}{l}\text { Amuru white } \\
\text { seed }\end{array}$ & $\begin{array}{l}\text { Amuru black } \\
\text { seed }\end{array}$ & \\
\hline Palmitoleic acid & $0.087 \pm 0.01$ & $0.115 \pm 0.01$ & $0.098 \pm 0.01$ & $0.109 \pm 0.008$ & $0.08 \pm 0.009$ & $0.117 \pm 0.019$ & 0.101 \\
\hline Palmitic acid & $9.87 \pm 0.58$ & $10.91 \pm 0.44$ & $10.8 \pm 0.67$ & $10.98 \pm 0.78$ & $9.345 \pm 0.88$ & $11.18 \pm 0.49$ & 10.64 \\
\hline Margaric acid & $0.035 \pm 0.003$ & $0.032 \pm 0.004$ & $0.036 \pm 0.006$ & $0.028 \pm 0.004$ & $0.03 \pm 0.004$ & $0.027 \pm 0.003$ & 0.031 \\
\hline Linoleic acid & $44.31 \pm 1.77$ & $42.5 \pm 2.99$ & $43.7 \pm 2.11$ & $43.3 \pm 2.96$ & $43.9 \pm 3.19$ & $44.0 \pm 3.10$ & 43.6 \\
\hline Oleic acid & $37.85 \pm 2.27$ & $38.88 \pm 3.94$ & $37.98 \pm 4.01$ & $38.18 \pm 3.11$ & $38.95 \pm 3.35$ & $37.19 \pm 2.24$ & 38.2 \\
\hline Cis-vaccenic acid & $0.778 \pm 0.09$ & $0.936 \pm 0.087$ & $0.811 \pm 0.076$ & $0.906 \pm 0.089$ & $0.78 \pm 0.071$ & $0.957 \pm 0.073$ & 0.861 \\
\hline Stearic acid & $6.335 \pm 0.55$ & $6.022 \pm 0.05$ & $6.523 \pm 0.074$ & $5.78 \pm 0.43$ & $6.238 \pm 0.51$ & $5.823 \pm 0.44$ & 6.12 \\
\hline Arachidic acid & $0.627 \pm 0.069$ & $0.595 \pm 0.06$ & $0.634 \pm 0.068$ & $0.588 \pm 0.061$ & $0.59 \pm 0.061$ & $0.596 \pm 0.039$ & 0.605 \\
\hline Behenic acid & $0.092 \pm 0.085$ & - & - & $0.093 \pm 0.01$ & $0.083 \pm 0.009$ & $0.094 \pm 0.012$ & 0.091 \\
\hline
\end{tabular}

to $6.523 \%)$, palmitic acid (9.345-11.186\%), oleic acid (37.19-38.95\%), linoleic acid (42.49-44.31\%) (Table 2). The coefficient of variation of these fatty acids was $<10$, which indicates the variability of these compounds in the studied samples, were minimal. Whereas palmitoleic acid (C16:1) and stearic acid (C18:0) with a coefficient of variation $15 \%$ and $45 \%$, respectively, indicated that these two compounds were widely varied with the studied samples.

In all the studied samples, the total unsaturated fatty acids were greater than $82 \%$ of the total fatty acid, which implies that sesame seed oil is the most preferred oil for consumption. The other interesting feature of this seed oil is that almost half of the fatty acid (43\%) is constituted from linoleic acid, an omega- 6 fatty acid, and an essential fatty acid for the human diet.
The fatty acid composition of white and black sesame seed varieties was compared with other reported seed oils from Ethiopia and overseas counties (Table 3). The fatty acid profiles obtained from the present study conformed to the trend reported in the literature for sesame seed oils. Unlike the other trace fatty acids, oleic acid and linoleic acids have shown broader ranges of variation between the present result and reported data (Table 3). This indicates the existence of some genetic variations with the studied and reported sesame seeds and/or environmental conditions between the cultivation regions [42].

Looking at Table 3, the fatty profile of black and white sesame seed varieties from Ethiopia had a similar profile with the fatty acid composition of sesame seed oil 


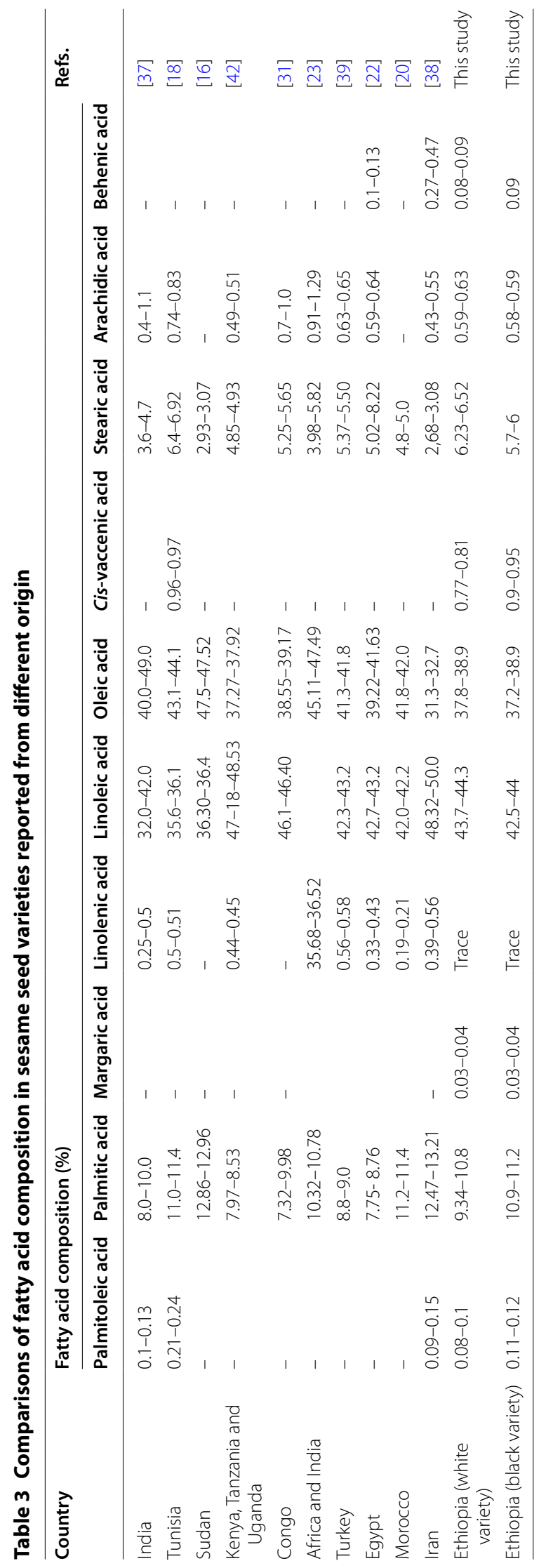


reported from Tunisia [18] and India [37] (Table 3). However, the major fatty acids were found to be higher in Ethiopian sesame seeds. For instance, the percent composition of the omega- 6 fatty acid (linoleic acid) is significantly higher in the present study (42-44\%) than sesame oilseed accession from Tunisia (35.6-36.1\%), Indian (32.0-42.0\%), Sudan (36.3-36.4), Africa and India samples (35.68-36.52) (Table 3). Whereas, a comparable linoleic acid composition (40-44\%) was reported by Ünal and Yalçın [39], Hassan [22] and Gharby et al. [20], respectively, from Turkey, Egypt, and Morocco (Table 3). On the other hand, a higher percent composition of this fatty acid was reported in Congolese and Iranian sesame oilseeds [31,38].

The Oleic acid content in Tunisian, Indian, Sudanese, Turkish, Egyptian, Moroccan, and Iranian sesame seed varieties were higher than (41-47\%) those found in the present study (37-39\%) (Table 3). However, a comparable results with the present study were reported for Kenyan, Tanzanian, Ugandan and Congolese sesame oilseeds samples [42], Nzikou et al. [31]. In addition, relatively much lower oleic acid was reported from Iranian sesame oilseed sample [38].

The major saturated fatty acid, palmitic acid composition (8-11\%) reported from some selected African and Asian countries were comparable with those found in the present study $(9-11 \%)$ (Table 3). However, a higher composition (13\%) were reported in Sudanese and Iranian sesame seed accessions [16, 38]. A similar trend was noted for the second major saturated fatty acid, stearic acid (Table 3), but a relatively lower composition of it was reported in Sudanese and Iranian sesame seed accessions $[16,38]$.

A higher composition of linoleic acid in the studied Ethiopian Sesame seed makes these sesame seed varieties to be nutritionally more important as compared to the Tunisian and Indian sesame seed types. Furthermore, cis-vaccenic acid (C18:1) was not identified in most of the reported sesame seed, while in Ethiopian sesame seeds, about $1 \%$ was noted. These variations might be due to variations in the genetic makeup of the seeds and agroecological conditions of the study areas.

Results of the present study were also compared with reported other Ethiopian oil seeds (niger seed and linseeds) and interestingly, there is a wide difference in the individuals fatty acid composition between these oilseeds. For example, niger seed is much richer in linoleic acid (C18:2) (73\%) and sesame seed (44\%). However, linseed has a significantly lower composition of this omega- 6 fatty acid (15\%). On the other hand, sesame seed varieties are richer in oleic acid (C18:1) (about 37\%) than niger seed (7\%) and linseed (20\%). Thus, this fatty could be a marker molecule for sesame seed oil. Secondly, cis-vaccenic acid (C18:1) was not reported in both niger seed and linseed $[19,40]$.

\section{Conclusion}

This study assessed the composition of phenolic compounds and fatty acid compositions of white and black sesame seeds collected from three major sesame oilseedproducing districts. Both white and black sesame seeds are composed of quantifiable amounts of total phenolic and flavonoid compounds ranging from 2.95 to 6.96 $\mathrm{mgGAE} / \mathrm{g}$ and $2.13-4.99 \mathrm{mgCE} / \mathrm{g}$, respectively. The sample extracts have demonstrated appreciable $\mathrm{IC}_{50}$ values ranging from 8.23 to $16.8 \mathrm{mgAAE} / \mathrm{g}$ of samples. In general, white sesame seeds are relatively richer in total flavonoid and phenolic compounds. On the other hand, sesame seeds collected from Metema districts had higher phenolic, flavonoids, and antioxidant activities.

The fatty acid analysis revealed that the seeds are composed of both saturated, monounsaturated, and polyunsaturated fatty acids. The two varieties of sesame seeds had a comparable composition of fatty acids. Among the nine fatty acids identified, $82 \%$ of the total fatty acids were composed of unsaturated fatty acids, which makes sesame seed is nutritionally important. The predominant polyunsaturated fatty acids components in the sesame seed varieties were linoleic acid (C18:2), which was ranging from 42.5 to $44.3 \%$ of the total fatty acid followed by the monounsaturated fatty acid, oleic acid (C18:1) which ranged from 37.2 to $38.9 \%$ of the total fatty acid. Both black and white sesame seed samples were rich in the omega- 6 fatty acid (linoleic acid) as compared to some other oil seeds. The saturated fatty acids constituted $<18 \%$ of the total fatty acids, of which palmitic acid (C16:0) constituted (9.3$11.2 \%)$ followed by stearic acid (C18:0) (5.78-6.52\%) of the total fatty acids.

\section{Supplementary Information}

The online version contains supplementary material available at https://doi. org/10.1186/s40538-021-00215-w.

Additional file 1: Figure (S1). GC-MS chromatogram of the fatty acid methyl esters of white sesame seed variety collected from Metema district. "IS" refers to the internal standard (undecanoic acid methyl ester). Figure (S2). GC-MS chromatogramof methyl esters of fatty acids present in Black sesame seed collected from Metema district. Figure (S3). GC-MS chromatogram of methyl esters of fatty acids present in white sesame seed collected from West Armachiho district. Figure (S4). GC-MS chromatogram of methyl esters of fatty acids present in Black sesame seed collected from West Armachiho district. Figure (S5). GC-MS chromatogram of methyl esters of fatty acids present in white sesame seed collected from Amuru district. Figure (S6). GC-MS chromatogram of methyl esters of fatty acids present in black sesame seed collected from Amuru district. 


\section{Acknowledgements}

The authors would like to acknowledge Bahir Dar University for providing Laboratory facility. Mr. Misganaw Gedlu Agidew is thankful to the Ministry of Science and Higher Education (MoSHE) of Ethiopia for sponsoring his study.

\section{Authors' contributions}

MGA and MA designed and conducted the experiment. MGA compiled the data, while MA, WA and AAD approved the data, edited and organized the manuscript. All the authors read and approved the final manuscript.

\section{Funding}

Not applicable.

\section{Availability of data and materials}

The datasets used and/or analyzed during the current study are available from the corresponding author on reasonable request.

\section{Ethics approval and consent to participate}

Not applicable.

\section{Consent for publication}

Not applicable.

\section{Competing interests}

The authors declare that they have no competing interests.

\section{Author details}

1 Department of Chemistry, College of Natural and Computational Science, Energy and Environment Research Center, Dilla University, 419 Dill, Ethiopia. ${ }^{2}$ Department of Chemistry, College of Science, Bahir Dar University, P. O. Box 79, Bahir Dar, Ethiopia.

Received: 15 October 2020 Accepted: 2 February 2021

Published online: 24 March 2021

\section{References}

1. Abebe NT. Review of sesame value chain in Ethiopia. Inte J Afr Asian Stud. 2016;19:36-47.

2. Abirached C, Bonifacino C, Dutto E, et al. Study of sesame seeds antioxidant and emulsifying properties original high-quality research paper. J Supercrit Fluids. 2020;166:104994.

3. Ali S, Jan A, Zhikuan J, et al. Growth and fatty acid composition of sesame (Sesamum indicum L.) genotypes as influence by planting dates and nitrogen fertilization in semiarid region of northwest. Pakistan Russ Agric S. 2016:42:224-9.

4. Anwar F, Przybylski R. Effect of solvents extraction on total phenolics and antioxidant activity of extracts from flaxseed (Linum usitatissimum L.). Acta Sci Pol Technol Aliment. 2012;11:293-302.

5. Aysheshm K (2007) Sesame market chain analysis: the case of Metema Woreda, North Gondar zone, Amhara national regional state (M.SC thesis, Haramaya University). https://hdl.handle.net/10568/3165. Accessed 7 Jul 2020

6. Azeez MA, Morakinyo JA. Genetic diversity of fatty acids in sesame and its relatives in Nigeria. Eur J Lipid Sci Technol. 2011;113:238-44.

7. Bayba KB, Dubale AA, Mehari B, et al. Chemical composition of Urtica simensis grown in different regions of Ethiopia. J Chem. 2020;2020:1-7.

8. Benitez-Benitez R, Ortega-Bonilla RA, Martin-Franco JAIME. Comparison of two sesame oil extraction methods: percolation and pressed. Rev Bio Agro. 2016;14:10-8.

9. Bentivoglio D, Savini S, Finco A, et al. Quality and origin of mountain food products: the new European label as a strategy for sustainable development. J Mount Sci. 2019:16(2):428-40.

10. Carvalho R, Galvão E, Barros J, et al. Extraction, fatty acid profile, and antioxidant activity of sesame extract (Sesamum Indicum L.). Br J Chem Eng. 2012;29:409-20

11. Charan S, Panghal A. Importance of traceability in food supply chain for brand protection and food safety systems implementation. Ann Biol. 2018;34:111-8.
12. Chellamutu M, Sekar P Subramanian S. Evaluation of sesame (Sesamum indicum L.) germplasm collection of Tamil Nadu for a-linolenic acid, sesamin, and sesamol content. Afr J Biotechnol. 2017:16:1308-13.

13. Dar AA, Kancharla PK, Chandra K, Sodhi YS, Arumugam N. Assessment of variability in lignan and fatty acid content in the germplasm of Sesamum indicum L. J Food Sci Technol. 2019;56(2):976-86

14. Dwiecki K, Siger A, Czubiński J, et al. The interactions between rapeseed lipoxygenase and native polyphenolic compounds in a model system. J Am Oil Chem Soc. 2012:89:379-87.

15. El Khier MKS, Ishag KEA, Yagoub A. Chemical composition and oil characteristics of sesame seed cultivars grown in Sudan. Res J Agric Biol Sci. 2008:4:761-6.

16. Ebrahimian E, Seyyedi SM, Bybordi A, et al. Seed yield and oil quality of sunflower, safflower, and sesame under different levels of irrigation water availability. Agri Water Manag. 2019;218:149-57.

17. Elleuch $M$, Besbes $S$, Roiseux $O$, et al. Quality characteristics of sesame seeds and by-products. Food chem. 2007;103:641-50.

18. Geleta M, Stymne S, Bryngelsson T. Variation and inheritance of oil content and fatty acid composition in niger (Guizotia abyssinica). J Food Comp Anal. 2011:24:995-1003.

19. Gharby S, Harhar H, Bouzoubaa Z, et al. Chemical characterization and oxidative stability of seeds and oil of sesame grown in Morocco. J Saudi Soc Agri Sci. 2017;16:105-11.

20. Hai Z, Wang J. Detection of adulteration in camellia seed oil and sesame oil using an electronic nose. Eur J Lipid Sci Tech. 2006;108:116-24.

21. Hassan MA. Studies on Egyptian sesame seeds (Sesamum indicum L.) and its products 1-physicochemical analysis and phenolic acids of roasted Egyptian sesame seeds (Sesamum indicum L.). World J Dairy Food Sci. 2012;7:195-201.

22. Hiremath SC, Patil CG, Patil KB, et al. Genetic diversity of seed lipid content and fatty acid composition in some species of Sesamum L. (Pedaliaceae). Afr J Biotechnol. 2007:6:539-43.

23. Kadkhodaie A, Razmjoo J, Zahedi M, et al. Oil content and composition of sesame (Sesamum indicum L.) genotypes as affected by irrigation regimes. J Am Oil Chem Soc. 2014:91:1737-44.

24. Lin X, Zhou L, Li T, et al. Phenolic content, antioxidant and antiproliferative activities of six varieties of white sesame seeds (Sesamum indicum L). RSC Adv. 2017;7:5751-8

25. Lule D, Mengistu G, Daba C, et al. Registration of Obsa and Dicho sesame (Sesamum indicum L.) varieties. East Afr J Sci. 2011;5:66-8.

26. Mehari B, Redi-Abshiro M, Chandravanshi BS, et al. GC-MS profiling of fatty acids in green coffee (Coffea arabica L.) beans and chemometric modeling for tracing geographical origins from Ethiopia. J Sci Food Agri. 2019;99:3811-23.

27. Mekonnen A, Atlabachew M, Kassie B. Investigation of antioxidant and antimicrobial activities of Euclea schimperi leaf extracts. Chem Biol Technol Agric. 2018;5(1):16.

28. Mistrello J, Sirisena SD, Ghavami A, et al. Determination of the antioxidant capacity, total phenolic, and flavonoid contents of seeds from three commercial varieties of culinary dates. Int J Food Stud. 2014:3:33-44.

29. Myint D, Gilani SA, Kawase M, et al. Sustainable Sesame (Sesamum indicum L.) production through improved technology: an overview of production, challenges, and opportunities in Myanmar. Sustainability. 2020;12:3515.

30. Nzikou J, Matos L, Bouanga-Kalou G, et al. Chemical composition on the seeds and oil of sesame (Sesamum indicum L.) grown in Congo-Brazzaville. Adv J Food Sci Technol. 2009:1:6-11.

31. Rebaya A, Belghith SI, Baghdikian B, et al. Total phenolic, total flavonoid, tannin content, and antioxidant capacity of Halimium halimifolium (Cistaceae). Appl pharm Sci. 2014;5:52-7.

32. Rincón-Cervera MÁ, Galleguillos-Fernández R, González-Barriga V, et al. Fatty acid profile and bioactive compound extraction in purple Viper's bugloss seed oil extracted with green solvents. J Am Oil Chem Soc. 2020;97:319-27.

33. Rizki H, Nabloussi A, Kzaiber F, et al. Comparative assessment of bioactive components, antioxidant effects from 15 cultivars of sesame (Sesamum indicum L.) for different crop years. Int J Sci Eng Res. 2018:9:462-8.

34. Sharma L, Singh C, Sharma HK. Assessment of functionality of sesame meal and sesame protein isolate from Indian cultivar. J Food Meas Charact. 2016;10:520-6.

35. Temesgen F, Gobena E, Megersa H. Analysis of sesame marketing chain in case of Gimbi Districts, Ethiopia. J Educ Pract. 2017:8:86-102.

36. Thakur V, Paroha S, Mishra RP. Free fatty acid profile of seven sesame (Sesamum Indicum L.) Verities. Int J Curr Microbiol App Sci. 2018:7:3439-53. 
37. Toorani MR, Farhoosh R, Golmakani M, et al. Antioxidant activity and mechanism of action of sesamol in triacylglycerols and fatty acid methyl esters of sesame, olive, and canola oils. LWT. 2019;103:271-8.

38. Ünal MK, Yalçın H. Proximate composition of Turkish sesame seeds and characterization of their oils. Grasas Aceites. 2008;59:23-6.

39. Wakjira A, Labuschagne MT, Hugo A. Variability in oil content and fatty acid composition of Ethiopian and introduced cultivars of linseed. J Sci Food Agri. 2004;84:601-7.

40. Wei $X$, Zhu $X, Y u$ J, et al. Identification of sesame genomic variations from genome comparison of landrace and variety. Front Plant Sci. 2016;7:1169-81

41. Were BA, Onkware AO, Gudu S, et al. Seed oil content and fatty acid composition in East African sesame (Sesamum indicum L.) accessions evaluated over 3 years. Field Crops Res. 2006;97:254-60.
42. Zeb A, Muhammad B, Ullah F. Characterization of sesame (Sesamum indicum L.) seed oil from Pakistan for phenolic composition, quality characteristics, and potential beneficial properties. J Food Meas Charact. 2017;11:1362-9.

43. Zerihun J. Sesame (Sesame indicum L.) crop production in Ethiopia: trends, challenges, and future prospects. Sci Technol Arts Res J. 2012;1:01-7.

\section{Publisher's Note}

Springer Nature remains neutral with regard to jurisdictional claims in published maps and institutional affiliations.

\section{Submit your manuscript to a SpringerOpen ${ }^{\odot}$ journal and benefit from:}

- Convenient online submission

- Rigorous peer review

- Open access: articles freely available online

- High visibility within the field

- Retaining the copyright to your article

Submit your next manuscript at $\boldsymbol{\nabla}$ springeropen.com 